\title{
The Evolution of Hazing: Motivational Mechanisms and the Abuse of Newcomers
}

\author{
Aldo Cimino* \\ Center For Evolutionary Psychology, Department of Anthropology, \\ University of California, Santa Barbara, CA 93106-3210, USA \\ *E-mail: aldo@aldocimino.com
}

\begin{abstract}
Hazing - the abuse of new or prospective group members - is a widespread and puzzling feature of human social behavior, occurring in divergent cultures and across levels of technological complexity. Some past research has examined the effect of hazing on hazees, but no experimental work has been performed to examine the motivational causes of hazing. This paper has two primary objectives. First, it synthesizes a century of theory on severe initiations and extracts three primary explanatory themes. Second, it examines the dynamics of enduring human coalitions to generate an evolutionary theory of hazing. Two laboratory experiments suggest that one potential function of hazing is to reduce newcomers' ability to free ride around group entry. These results are discussed in light of two common but largely untested explanations of hazing.
\end{abstract}

\section{Keywords}

Hazing, initiations, newcomers, coalitional psychology

Hazing is the abuse of new or prospective group members (collectively, "newcomers"). Hazing and initiations have fascinated social scientists for at least a century (e.g., Webster, 1908; Gennep, 1909; Loeb, 1929; Miller, 1932; Eliade, 1958; Muuss, 1970; Barth, 1975; Schlegel and Barry, 1979; Tiger, 1984; Herdt, 1998). The startling variety of ordeals and privations suffered by hazees includes physical assaults, scarification, sleep deprivation, servile labor, and many others. Hazing is common throughout much of the world, including modern, industrialized countries (e.g., Butt-Thompson, 1908; McCarl Jr., 1976; Schlegel and Barry, 1979; Lewis, 1992; Shaw, 1992; Hoover, 1999; Hoover and Pollard, 2000; Gershel et al., 2003; Jeong, 2003; de Albuquerque and Eduardo, 2004; Parks and Brown, 2005; Allan and Madden, 2008). Time and again, new coalitions ${ }^{1}$ form, persist for some time, and then invent or adopt hazing practices.

${ }^{1}$ By "coalition" I have in mind relatively cohesive groups such as secret societies, fraternal and 
But what specific psychological processes cause people to haze? Although some experimental research has examined hazing's effect on hazees (e.g., Aronson and Mills, 1959; Schopler and Bateson, 1962; Enge, 1993), there are no experimental studies that investigate hazing motivation at the individual level. This paper attempts to fill this gap by exploring the possible role of evolved motivational systems in generating and sustaining hazing behavior. To do so, I will first provide a provisional definition of hazing and review the major theoretical claims made about hazing behavior. Second, I will examine two foundational theories of hazing from an explicitly evolutionary perspective, comparing real-world observations of hazing behavior to the core predictions of these theories. Finally, I will attempt to extend the logic of these theories and report on two experimental studies of a cognitive, motivational theory of hazing.

\section{A Provisional Definition of Hazing}

The present analysis assumes that hazing is logically - and psychologically separable from initiations and ritual in general. For instance, some groups haze outside of formalized initiations and many initiations occur without hazing (e.g., Schlegel and Barry, 1979; Lewis, 1992; Nuwer, 2000). Hazing is defined here as the generation of induction costs (i.e., part of the experiences necessary to be acknowledged as a "legitimate" group member) that appear unattributable to group-relevant assessments, preparations, or chance. For example, the energetic cost of running while trying out for a men's track team is a product of a group-relevant assessment. If the track team were to mandate that prospective members dress in women's clothing for the same activity, any additional costs (energetic or social) do not appear relevant to the group's task domain. Logically, hazing may also be manifest in unduly excessive assessments or preparations. Thus, "group relevance" encompasses both the content and the intensity of an induction experience.

By this definition, hazing is not simply the sum of a group's unpleasant induction activities. To illustrate, imagine a club whose sole purpose is to hold cinder blocks for five hours a day. If this club ("The Block Holders") asks the same of prospective members, they are asking for the performance of a grouprelevant task, presumably to assess whether candidate members are capable of holding heavy cinder blocks. Such a requirement is legitimately unpleasant, but it closely reflects what the group does on a regular basis. Conversely, if the

sororal associations, society-wide associations of males, etc. (cf., Bates and Babchuk, 1961; Tooby et al., 2006). 
block-holding requirement is transplanted to a reading club, its purpose becomes much less transparent. This definition renders some classic examples of hazing questionable - basic training in the military may be profoundly unpleasant, but much of it is likely understandable in non-hazing terms. ${ }^{2}$

This provisional definition is not an ontological claim. Even the most bizarre hazing behaviors may turn out to be explicable in terms of group-relevant assessments or preparations (e.g., Keating et al., 2005). However, testing whether this is the case requires a definition that distinguishes hazing from other aspects of group inductions. This definition makes explicit the aspect of costly inductions that has likely held the attention of generations of social scientists.

\section{The Theoretical Landscape of Hazing}

Unfortunately, much of the literature that is pertinent to the study of hazing does not concern "hazing" in the precise sense defined in this paper (e.g., Hoover, 1999; Nuwer, 2000; Van Raalte et al., 2007). Further, many researchers have theorized about phenomena that may include a non-trivial hazing component (such as adolescent initiations), but have not designed their theories to explain hazing itself or hazing outside of certain populations (Cohen, 1964; Young, 1965; Granzberg, 1972; Grimes, 2000; Sosis et al., 2007; but see Cialdini, 2001; Keating et al., 2005). Consequently, many of the theories that are relevant to hazing operate at different levels of analysis and are not strictly comparable. Nonetheless, there are three persistent themes in the explanations given (or implied) for hazing, even in widely different contexts. ${ }^{3}$ It is these three themes - these "macro theories" - that I will use to organize the literature.

By macro theory, I mean an umbrella theory that encompasses the many possible mediators of some contributor to hazing's genesis or persistence. Simply stated, these theories are (a) hazing generates group solidarity; ${ }^{4}$ (b) hazing is an expression of dominance; and (c) hazing allows for the selection of

\footnotetext{
2 This is not to imply that hazing is absent from military organizations. See discussions in Dornbusch (1955), Winslow (1999), Ostvik and Rudmin (2001), and Pershing (2006).

3 I emphasize that few of the researchers cited are constructing "hazing theories" in an explicit and purposeful sense. I mean only that their writings suggest or imply the existence of a causal process underlying the abuse of new or prospective members in one or more contexts.

4 There is a broad sense in which many hypothesized effects of hazing may contribute to some definition of "group solidarity" (e.g., selecting for committed members may help the group function better). Thus, the macro theory of solidarity is that hazing increases group cohesion (i.e., efficiency, effectiveness, or social harmony) by some means that is not logically dependent on the macro theories of commitment or dominance.
} 
committed group members. Because most explanations of hazing are recapitulations of these core ideas, there is an implied consensus in the social sciences that one or more of the macro theories is true. While the macro theories do not exhaust the actual or possible theories of hazing, they are the most common and most generalizable frameworks (for other applicable theories, see Bettelheim, 1954; McCauley and Lawson, 2002; Whitehouse, 2004; Wilson, 2008).

Consider, first, the solidarity macro theory. One of the most well-known implementations of the solidarity macro theory uses social psychology's concept of cognitive dissonance (for a recent review of cognitive dissonance, see Harmon-Jones and Harmon-Jones, 2007). Originally outlined by Aronson and Mills (1959), the basic hypothesis is that individuals who undergo hazing justify their high levels of effort by increasing their liking for the hazing group. Note, however, that cognitive dissonance is simply a candidate mediator of the solidarity macro theory - it is a possible way for hazing to increase hazees' valuation of the group. Similarly, Keating et al. (2005) have argued that the over-arching purpose of hazing is to create "dependence," whereby abused individuals increase their liking of their abusers (as in Stockholm Syndrome). Again, this is a hypothesized way for hazing to generate an increase in intragroup valuation (see also Schopler and Bateson, 1962; Tuzin, 1980). These social-psychological theories represent just a few instantiations of the solidarity macro theory. Innumerable others throughout the social sciences have suggested or implied that hazing contributes to group solidarity in one context or another (e.g., Webster, 1908; Miller, 1932; Bloch and Niederhoffer, 1958; Whiting et al., 1958; Cohen, 1964; Smith, 1964; Young, 1965; Turner, 1967; Walker, 1968; Anderson and Noesjirwan, 1980; Tiger, 1984; Aronson, 1988; Decker and Van Winkle, 1996; Vigil, 1996; Weisfeld, 1997; Wiessner et al., 1998; Winslow, 1999; Johnson, 2000; Wintrup, 2004; Alcorta and Sosis, 2005; Parks and Brown, 2005; van Rooyen et al., 2006).

In apparent contrast to the solidarity macro theory is the dominance macro theory. The idea that hazers are seeking to establish or reaffirm a dominant position with respect to hazees is very common. Consider a few examples: Durkheim (1912) notes that group members haze newcomers to "make them understand how superior [they feel]" (p. 318). Bryshun (1997) writes that athletic hazing allows veterans to have their dominant position "consolidated" (p. 100). Whiting (1958) argues that hazing in male adolescent initiations is used to suppress "open and violent revolt" (p. 361). Honeycutt (2005) describes veterans of a discussion group hazing to "maintain their power" (Analysis section, final paragraph). Robidoux (2001) describes athletic hazers "celebrating their power over rookies" (p. 104). Keating et al. (2005) suggest 
that vertically-organized groups use severe initiations to "establish social control" (p. 107). Waldron and Kowalski (2009) write that athletic hazing rituals "help maintain...the power structure of the team" (p. 292). Nuwer (2000) actually defines hazing as an imposition of dominance, stating that hazing involves "any activity that requires new members to show subservience to old members" (p. 20), and so on (e.g., Webster, 1908; Stone, 1946; Johnson, 2001; Allan and DeAngelis, 2004; Tooby et al., 2006). The dominance macro theory is clearly a response to the manifest content of hazing, that is, the humiliating nature of many hazing practices and the humble, passive behavior expected of hazees.

Finally, the commitment macro theory is also well represented. Vigil (1996) writes that severe gang initiations act to "weed out the weak and uncommitted" (p. 151). Smith (1964) suggests that lengthy fraternity inductions are "contrived for the pledging of commitment" (p. 29). Johnson (2000) writes of athletic hazees having to "prove their commitment" (p. 70). Iannaccone (1992) argues that painful initiations "screen out free riders" (p. 11). Moreland and Levine (2002) describe harsh initiations as "testing how committed newcomers are" (p. 191). Tiger (1984) theorizes that male hazing is "analogous to mate selection in the reproductive sphere" (p. 135). Jones (2004) suggests that the pledges of fraternities are hazed to "prove their worth" (p. 59), and so on (e.g., Aronson and Mills, 1959; Paige and Paige, 1981; Bryshun, 1997; Boyer, 2001; Malszecki, 2004; Sosis et al., 2007). If one considers non-coerced, costly inductions in a market of prospective members, there is a minimal sense in which some of the social processes required by the commitment macro theory are likely true in practice, even if not in purpose. That is, all else held equal, groups with costly inductions will be more discouraging to uncommitted inductees.

The preceding description of the macro theories has been rendered in very broad terms to account for the variation in mechanisms and levels of analysis. Of note, most of the cited researchers implicitly support more than one macro theory. Each quote identifies just one aspect of a given researcher's approach to hazing or hazing-inclusive practices. Such theoretical complexity is understandable - hazing is a multifaceted phenomenon that almost certainly lacks a single, causal explanation. Nonetheless, making progress on understanding hazing may require starting with simpler, less inclusive theories. Such theories can focus on identifying experimentally tractable - and hopefully dissociable components of hazing. Ideally, these smaller theories can be combined to generate a more complete and comprehensible picture of the phenomenon.

This paper focuses on analyzing hazing in light of two of the macro theories: commitment and dominance (I leave an exploration of the solidarity 
macro theory to future work). To do so, I will formulate simple, testable versions of the commitment and dominance macro theories and attempt to match their predictions with extant naturalistic data on hazing behavior. I will then isolate predictions made by both theories that fall short of available evidence, propose a contributory theory, and test its basic predictions with two laboratory experiments. However, generating coherent, testable versions of the commitment and dominance macro theories requires a plausible description of the general psychology that might underlie hazing motivation. In other words, what kind of mind hazes?

\section{Hazing and the Nature of Intergenerational Coalitions}

By definition, hazing is a phenomenon that occurs around the time that new members are integrated into an extant coalition. Thus, how the mind understands "newcomers" may be crucial to explaining why hazing occurs. Consider the process that generates significant differences in tenure length between members: staggered group entry over time. This process produces multiple overlapping membership generations. Staggered group entry is not a logical necessity - one can at least imagine a world in which all enduring coalitions consist solely of their founding members. Thus, the recurrent practice of newcomer integration suggests the practice has (or had in our evolutionary past) at least some value. Newcomers may contribute a host of benefits, including additional labor inputs, unique skills, social connections outside the group, etc. (e.g., Cini et al., 1993; Cimino and Delton, 2010). That said, the benefits associated with newcomers are potentially offset by their costs. Newcomers increase coordination problems simply by increasing the size of the group and may be habitual free riders. That is, they may take the benefits associated with being a coalition member without paying the costs of maintaining these benefits in the future (e.g., Smith, 1964; Van Maanen and Schein, 1979; Iannaccone, 1992; Cini et al., 1993; Moreland and Levine, 2002; Sosis et al., 2007; Delton and Cimino, 2010). Solving the problems posed by free riders is considered critical to the evolution of cooperation in humans (see discussion in Price et al., 2002).

Note that the existence of intergenerational coalitions and the associated costs and benefits of newcomers are not simply artifacts of modern environments. At a basic level, these features of social life have likely persisted throughout much of human evolution. Consistent with this assumption, around the world, coalition newcomers appear to have a kind of visual and conceptual salience. They are often carefully attended to, pushed through rituals, oddly celebrated or punished, made to wear distinctive attire, given epithets (e.g., 
“greenhorn,” "F.N.G.”; see Carus, 1909; Bey, 1972). The common recurrence of these cultural forms may reflect an evolved ambivalence towards newcomers. Indeed, because the regular induction of newcomers likely played a role in the relative success of coalitions, humans may have an evolved concept of newcomer - a series of cognitive subroutines that generate adaptive responses to new coalition members. For example, experiments from Cimino and Delton (2010) suggest that subjects implicitly categorize coalition members by tenure (including newcomers) and ascribe especially low levels of trustworthiness and entitlement to newcomers, even when deprived of all characterological information.

If there is psychological design geared towards newcomers and group integration in general, might there be psychological design "for" hazing? While it is unlikely that there is any single-purpose, dedicated hazing adaptation, certain aspects of hazing motivation may be part of the proper domain of cognitive mechanisms designed for coalitional psychology (cf., Tooby et al., 2006; Sosis et al., 2007). That is, some of the mechanisms designed to solve adaptive problems associated with newcomers may license inferences and generate motivational states designed to prompt at least some of what is called "hazing."

Given that trust and commitment appear central to the adaptive problems generated by newcomers, the commitment macro theory represents a logical starting place in generating a theory of hazing motivation. ${ }^{5}$

\section{A Basic Commitment Theory of Hazing}

Humans are designed to attend to cues that suggest how others value them and store these inferred magnitudes as cognitive variables (Tooby et al., 2008). One such variable is intrinsic valuation: the willingness of a given agent to make unmonitored decisions that favor the self or allies. When an individual represents a conspecific's level of intrinsic valuation with a high degree of uncertainty, this may trigger motivational states that increase monitoring of cues to valuation and, in some circumstances, manufacture situations that hasten the receipt of such information. Members of enduring coalitions repeatedly encounter agents whose intrinsic valuation of their group is subject

\footnotetext{
${ }^{5}$ It is important to differentiate between the commitment macro theory (a term meant to encompass hazing as a means of selecting committed members) and the costly signaling theory of ritual. Researchers using the latter theory sometimes invoke multiple macro theories in describing and explaining hazing-inclusive phenomena (e.g., Alcorta and Sosis, 2005; Sosis et al., 2007; Bulbulia, 2008). As such, the commitment macro theory represents a comparatively restricted set of ideas.
} 
to a high degree of uncertainty - newcomers (Van Maanen and Schein, 1979; Moreland and Levine, 2002; Sosis, 2003; Delton and Cimino, 2010; Cimino and Delton, 2010).

Evidence indicates that new coalition members are selected at least partly on their perceived commitment to the group and that coalitions with cooperative interdependence place an even greater value on the commitment of prospective members (Cini et al., 1993; Cottrell et al., 2007; Stiff and Van Vugt, 2008). As discussed above, selecting committed members is important, as individuals with very low levels of intrinsic valuation may habitually free ride or defect during collective actions.

Note that, in the abstract, any non-trivial hazing accepted by new or prospective members may serve as a cue of their intrinsic valuation of the coalition (e.g., Iannaccone, 1992; Boyer, 2001; Moreland and Levine, 2002; Sosis et al., 2007). Indeed, hazing often involves enduring some ordeal that has little direct benefit for the hazer (e.g., eating nauseating substances, tolerating sleep deprivation, performing exhausting calisthenics). Participation in these activities may indicate that a new or prospective member is willing to endure high costs to impart even small benefits. Hazing, then, is at least theoretically efficient at hastening the receipt of information about intrinsic valuation. What predictions does this basic theory make about the structure of hazing behavior in the real world? One prediction is that hazing should be conducted in a way that does not divorce the actions of hazees from their intrinsic valuation of the coalition. Thus, during hazing ordeals, hazees should not be coerced, deceived, or confused in ways that would lessen the cue value of their participation (e.g., intimidating hazees to induce compliance). These basic predictions are strongly disconfirmed by real-world hazing, which is rife with all of these information-limiting characteristics (e.g., Whiting et al., 1958; Anderson and Noesjirwan, 1980; Baier and Williams, 1983; Colton, 1993; Hunter, 1996; Whitehouse, 1996; Bryshun, 1997; Herdt, 1998; Houseman, 2001; Johnson, 2001; Jeong, 2003). In my own field work with a pseudonymous college fraternity ("Alpha"), I have continually witnessed veteran members surround prospective members and begin yelling for a hazing ordeal to be completed. Being surrounded by a group of angry, screaming men is generally motivating for reasons separable from one's intrinsic valuation. These occurrences are not occasional responses to reluctance - they are part of a systematic effort to intimidate and confuse hazees.

To be clear, the issue is not that coercive hazing is incapable of providing any information about intrinsic valuation. In the specific case of college fraternities, multiple hazing events are spread out over a number of weeks. Because fraternities are voluntary associations, the time between events allows 
prospective members to withdraw from the group entirely. Continued participation, by contrast, implies some level of commitment. But this line of reasoning still leaves the coercion within hazing events completely unexplained. That is, if hazing exists to generate accurate inferences of intrinsic valuation, why should it ever be coerced? Presumably, what a prospective member will assent to while surrounded and monitored by the entire coalition (as well as exhausted, sleep deprived, nauseated, etc.) is an inaccurate measure of what said member will assent to while uncompromised and unmonitored.

Additionally, it is noteworthy that hazing occurs in non-voluntary associations. Many small-scale societies have men's associations or cults with obligatory inductions for all males (e.g., Webster, 1908; Precourt, 1975). Because participation is obligatory, the mere presence of an inductee is arguably a less reliable cue of intrinsic valuation than the mere presence of a fraternity pledge. And yet these obligatory hazings show many of the same anomalous characteristics seen in fraternity hazing (e.g., induced fatigue, coercion). Thus, the question remains: Why is hazing executed in ways that make inferring intrinsic valuation more difficult?

From the perspective of the basic commitment theory, another oddity of hazing is that it is almost entirely unidirectional: Veterans inflict hazing on newcomers, but newcomers do not inflict hazing on veterans. ${ }^{6}$ Rather than taking this regularity as a given, it should be regarded as a puzzle. After all, newcomers face some of the same informational uncertainties as veterans: Newcomers do not know whether veterans will defect or free ride on their own labor. Logically, veterans could first (non-coercively) haze newcomers and then allow themselves to be (non-coercively) hazed by these same newcomers. Doing so would allow for the exchange of mutual, high-value cues of intrinsic valuation. As an example of what such behavior might look like, consider Walker (1968). Walker examined fraternity hazing practices at the University of Washington, requiring that he gain the trust of multiple informants from different fraternities. One method of gaining their confidence was "trading hacks". To trade a hack is to willfully allow one's self to be paddled on the buttocks and to then reciprocate in kind. Trading hacks is a painful experience that (according to Walker) is designed to express mutual trust. It contains role

\footnotetext{
${ }^{6}$ The claim being made is not that mutual hazing never occurs, but rather that it does not represent how hazing is typically conducted. Even apparent examples of mutual hazing can be misleading. For instance, "reverse hazing" events have been documented in college fraternities, where prospective members are tasked with performing a one-time prank on veterans. Notably, these events are short-lived and trivial compared to the hazing received by the prospective members. Further, some reverse hazing events appear as though they were designed to provide a justification for punishment by veterans (e.g., Walker, 1968; Leemon, 1971).
} 
reversal as well as a traditional instrument of fraternity hazing (the paddle). And yet a careful reading of Walker (1968) suggests that trading hacks is either uncommon or absent in the hazing processes he documented. Instead, it appears to be a practice that exists among current fraternity members. Note that trading hacks is an example of what most real-world hazing could look like, but somehow does not. Further, it is a demonstration that hazers may understand (implicitly) the logic of mutual, non-coercive hazing, which prompts questions as to why it is not the predominant form of hazing.

In summary, certain characteristics of hazing appear to allow for the selection of members with high levels of intrinsic valuation. Specifically, in a market of prospective members, a high-cost induction will presumably discourage those who desire only short-term association (and, thus, short-term benefits). That said, there are other characteristics of hazing (e.g., coercion), as well as hazing's presence in non-voluntary associations, that suggest that generating accurate inferences of intrinsic valuation is not the only function of hazing and may not be its primary function.

\section{A Basic Dominance Theory of Hazing}

The above discussion of coercion and unidirectionality in hazing naturally prompts questions about the role of dominance in hazing. As explained in the discussion of the macro theories, hazing is sometimes characterized as an attempt to establish or reaffirm dominance over newcomers. Here, I assume that individuals who are dominant over others have differential access to valued resources by virtue of their ability to inflict costs (physical or social) on less dominant individuals (e.g., Ermer, 2008). Thus, one might conceive of hazing as a kind of aggressive dominance display or contest, where veterans are the inevitable winners. Are there any problems with this account of hazing? For one, hazing often occurs within an organized ceremonial or ritualistic context. These contexts can implicitly or explicitly communicate that the activities therein are separate and distinct from everyday life (e.g., Boyer, 2001). This is important, as it makes little sense for hazers to introduce doubt as to whether hazing reflects the dominance hierarchy once the hazing process is complete. From the perspective of the basic dominance theory, hazing should be a real-world attack or display, with little to no ambiguity as to its meaning. Within my own field work, this is not how hazing is framed by hazers. For instance, veterans of Alpha will commonly say to hazees that hazing is "just business." By this they mean, "when I haze you, it is not personal." They say this to reduce the perception that hazees are facing a direct physical contest. If hazing were a straightforward dominance display, one might expect 
them to say something akin to, "when I haze you, you should never forget it." To be clear, members of Alpha always attempt to be scary and intimidating to prospective members, but they also attempt to qualify their hazing in ways that suggest that the hazing process is different from everyday life. While Alpha is only one group, hazer/hazee relationships in other groups appear to contain implicit mutual knowledge that their interactions do not reflect the normal social order (e.g., Turner, 1967; Houseman, 2001). That is, it is understood that hazers can order hazees around, make ridiculous demands and inflict high costs, but at a certain point, they must cease doing so.

Regardless, even if hazing is set apart from the normal social order, perhaps it still communicates an implicit difference in dominance. After all, establishing dominance may not require explicit communication or regular reinforcement, only a credible demonstration of relative formidability. However, the basic dominance theory predicts that the result of this demonstration will be evident post hazing. Post-hazing newcomers should show an appropriate level of deference to veterans, with veterans reacting punitively otherwise. "Appropriate" levels of deference are difficult to test because even newcomers to nonhazing coalitions have less status than veterans (e.g., Van Maanen and Schein, 1979; Cimino and Delton, 2010). As such, it is not a confirmation of the basic dominance theory to find that post-hazing newcomers are not the equals of veterans. More importantly, there is a regularity of hazing that appears inconsistent with the idea that hazing is a one-time dominance display: hazees always increase in status once they have completed their hazing process. That is, once hazing is done, newcomers are no longer required to perform the ordeals or servile labor associated with their status as hazees, and they typically gain additional access to coalition benefits (e.g., prestige, property). This is important, as there is no necessity for veterans to cede any of the dominance that they have (by this theory) worked to create. In the case of Alpha, individuals who have completed the hazing process can no longer be made to clean the fraternity house on command, perform personal favors for veterans, greet veterans with submissive gestures (e.g., head down, no eye contact), etc. Veterans will even joke with post-hazing newcomers about their past dictatorial relationship, with both parties laughing (A paraphrased example: Veteran: "Hey, bring me my dinner!" Newcomer: "Nah."). Events such as these clearly communicate that the status of newcomers has risen post-hazing, making any dominance evident during hazing profoundly exaggerated relative to the actual social hierarchy. While not all hazing coalitions have such casual, egalitarian relations between newcomers and veterans, it seems inescapable that the end of hazing means a relaxation of their relative difference in status.

In summary, certain hazing behaviors (e.g., intimidation) look like dominance displays, while certain behaviors demanded of hazees look like cues of 
submission (e.g., lowered eyes). As such, some hazing experiences may leave lasting impressions on newcomers that influence their willingness to cede resources to veterans post hazing (e.g., Keating et al., 2005). That said, other characteristics of hazing appear anomalous from the perspective of the basic dominance theory. The mutually acknowledged "separateness" of the hazing period suggests that, in the least, it is not a normal dominance display. Further, the shared understanding that hazing will end with an increased status for newcomers makes any dominance established by hazing seemingly temporary.

\section{Explaining Some of Hazing's Anomalous Characteristics: Automatic Accrual Theory}

I have identified some characteristics of real-world hazing that seem anomalous in light of two basic implementations of the commitment and dominance macro theories. Essentially, hazing practices appear coercive, unidirectional (i.e., focused on newcomers), temporary, and not an accurate representation of the coalition's dominance hierarchy post hazing. One possibility is that these anomalous characteristics are a product of one or more functions of evolved hazing motivation that are not described by the basic commitment or dominance theories. How might one explain these characteristics?

I have suggested that humans have an evolved concept of NEwCOMER. This concept instantiates a set of adaptive responses to new coalition members, among them anti-exploitation responses (e.g., an initial reduction of trust and entitlement). These responses may function, in part, to prevent newcomers from successfully free riding on coalition benefits. Ancestrally, however, it was not simply the existence of generalized "group benefits" that allowed coalitions to be exploited by newcomers. It was specifically those benefits freely consumable upon group entry - automatic benefits - that were most at risk of exploitation (e.g., status, group protection, common property). ${ }^{7}$ In contrast, benefits with a slow or costly accrual period - non-automatic benefits - were at little risk of exploitation (e.g., knowledge of difficult, specialized skills). Ancestral newcomer exploitation may have taken at least two forms. First, newcomers might join a coalition and contribute nothing, accruing automatic benefits until successfully excluded (cf., Ehrhart and Keser, 2009). Second, newcomers

\footnotetext{
7 Most (if not all) of these benefits qualify as club goods or common-pool resources for the coalition in question. My use of the term "automatic benefits" is simply to group them together and highlight their likelihood of low-cost consumption by newcomers.
} 
might simply increase free riding behaviors aroundthe time of group entry, but reduce or cease this strategy as their tenure increases. Why might the second strategy be profitable? In the real world, judgments of whether an individual is free riding are made relative to that individual's task-specific competence and condition (e.g., Delton et al., 2006). For example, in a collective action where all participants are expected to construct baskets, there may exist natural variance in basket-constructing competence, due to differences in age, physical condition, and practiced skill. An individual who is understood to be legitimately poor at constructing baskets is unlikely to be seen as free riding when producing fewer baskets than others (Gurven, 2006). Being a newcomer to a coalition means that one's competence and trustworthiness as a coalition member are known with less accuracy. This informational uncertainty will make real-world free riding more difficult to detect. Ancestrally, if free riding around the time of coalition entry was more difficult to detect and if there were large benefits available for members who contributed nothing (i.e., high automatic benefits), free riding might have been more common among newcomers of enduring coalitions. As such, anti-free riding mechanisms may have been designed to motivate increasing the costs (and reducing the automatic benefits) for low-tenure members (cf., Honeycutt, 2005; Tooby et al., 2006; Sosis et al., 2007). This would presumably reduce the payoffs associated with near-term free riding. Additionally, establishing a level of dominance and control during a period of otherwise heightened exploitation would allow for veterans to guarantee at least some labor inputs and demonstrate a temporarily increased willingness to inflict costs for social violations (for examples of enforced labor in hazing, see Webster, 1908; Svaan, 1967; Gordon et al., 1979; Baier and Williams, 1983; Shaw, 1992).

Because the above theory focuses on automatic group benefits, I will refer to it as "automatic accrual theory." In this paper, I will test four basic predictions of automatic accrual theory:

1. Because strongly cooperative groups generate high levels of automatic benefits, membership in these groups will motivate greater hazing severity than membership in weakly cooperative groups (effectively, this difference in hazing severity will be mediated via differences in automatic benefits).

2. If hazing is designed, in part, to prevent the exploitation of automatic benefits, non-automatic benefits will predict no unique variance in hazing severity when automatic benefits are statistically controlled.

3. Because being a high contributor to a group entails disproportionate contribution to the maintenance of automatic benefits, members with high levels of contribution will haze more severely than members with low levels of 
contribution. Presumably, these members value the coalition more and will be differentially motivated to prevent its exploitation.

4. If hazing is designed, in part, to create costs that prevent or discourage near-term exploitation, hazers should be increasingly willing to coercively inflict these costs as the chance of exploitation increases. In other words, if hazing severity reflects the likelihood of exploitation by newcomers (see prediction 1), it will positively predict hazing coerciveness.

These predictions were tested with two vignette-based experiments wherein participants were given an opportunity to indicate their desire to haze newcomers.

\section{Experiment 1: Automatic Benefits and Desired Hazing Severity}

\section{Participants}

132 participants (44 male) between the ages of 18 and $30(M=19.56, \mathrm{SD}=2.06)$ were recruited from a UC Santa Barbara physical anthropology course (hazing and initiations were not discussed in the course). Course credit was given for participation.

\section{Materials and Procedure}

Participants were randomly assigned to complete questionnaires about two strongly cooperative groups (i.e., high levels of cooperative interdependence) or two weakly cooperative groups. Each questionnaire described typical group activities and instructed participants to imagine themselves as current members. Group descriptions also contained pictures of individuals engaged in group-relevant tasks. Within each group type (strongly cooperative vs. weakly cooperative), order of group presentation was counterbalanced. Following each group description, participants read that they were either high group contributors (i.e., they expended high effort in group activities, volunteered to provide additional help when needed, etc.) or low group contributors. The order of contribution primes was counterbalanced. To control for generalized sex differences in aggressiveness, sex was included as a predictor variable. In sum, the study used a $2 \times 2 \times 2$ mixed-model design: group type (strongly cooperative $v$ s. weakly cooperative: between $) \times$ contribution (high vs. low: within) $\times$ participant sex $($ male $=1$, female $=0)$. 


\section{Non-Manipulated Questionnaire Components}

Membership in each group was described as contingent on two criteria: (i) the ability to get along with existing members and (ii) the possession of grouprelevant skills or attributes.

Participants read that the group had recently decided to have an initiation for new members. As current members, participants were allowed to shape the initiation. Their options consisted of (a) whether the initiation should have a pleasant component, and if so, how pleasant; (b) whether the initiation should have a stressful component, and if so, how stressful; and (c) whether new members should be pressured to complete the initiation, and if so, to what extent. This was followed by a series of questions about how the group will benefit new members, including (a) to what extent joining the group will increase the status of new members in the eyes of non-members; (b) to what extent joining the group will provide new members with a coalition that will protect them outside of typical group activities; and (c) to what extent joining the group will increase two different group-relevant skills or traits, rated separately. All questions were answered on five-point rating scales (0-4).

\section{Groups Used in Vignettes}

All groups were fictional and designed to be relatively unfamiliar to participants (i.e., no publicly known hazing status). The following are summaries of the group descriptions provided to participants:

Ice Walkers (strongly cooperative): The Ice Walkers are a group of arctic survival specialists. The Ice Walkers go on expeditions to remote, mountainous locations. While on expeditions, the group must fend for itself and work together to hunt, climb, and carry vital supplies.

Aid Workers (strongly cooperative): The Aid Workers are a group of international Emergency Medical Technicians that operates in war-torn countries. While on assignment, the group is sometimes under fire and must depend on each other to assist in tense medical situations.

Bug Watchers (weakly cooperative): The Bug Watchers are a group of insect enthusiasts. They meet to give presentations on various insect species and organize trips to relevant museums.

Audiophiles (weakly cooperative): The Audiophiles are a group of stereo and audio enthusiasts. They meet to attend relevant conventions and compete to have the best stereo systems. 


\section{Operationalization and Composite Variables}

"Desired hazing severity" was operationalized as the advocated stressfulness of the initiation. "Automatic benefits" were operationalized as the sum of the status benefit and the protection benefit. "Non-automatic benefits" were operationalized as the sum of the group-relevant skill/trait benefits, which varied by group (for example, the Ice Walkers' non-automatic benefits consisted of physical fitness and arctic survival skills).

Results

All significance tests are two-tailed. Effect sizes use Cohen's $d$. Only significant interactions are reported.

Did Participants Haze More Severely in Strongly Cooperative Groups than in Weakly Cooperative Groups?

Yes; participants desired more severe hazing in strong groups $(M=2.49$, $\mathrm{SD}=0.93)$ than in weak groups $(M=1.08, \mathrm{SD}=0.78)$. The effect was large: $d=1.64, F(1,128)=75.17, p<0.001$.

Did Automatic Benefits Appear to Mediate the Effect of Group Type on Hazing Severity?

Yes; controlling for automatic benefits reduced the amount of variance in desired hazing severity that can be uniquely explained by group type (Fig. 1).

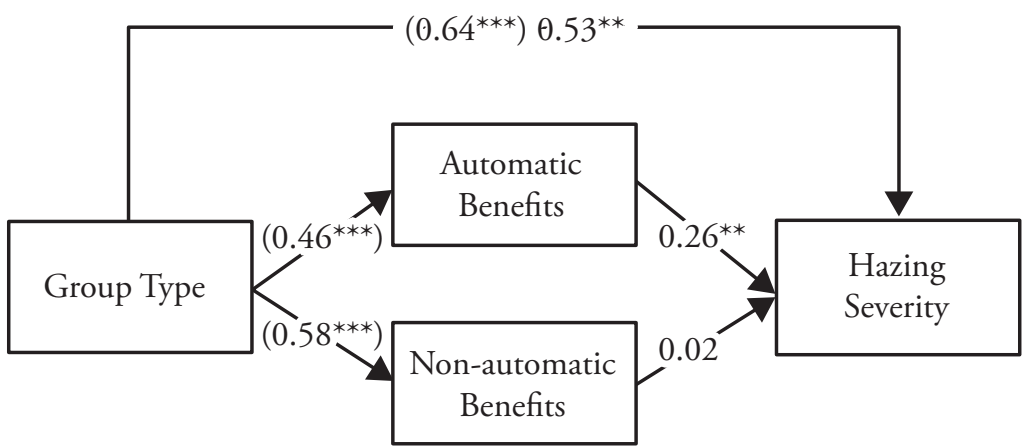

Figure 1. (From Experiment 1) All non-parenthetical values are standardized beta coefficients from an OLS regression predicting hazing severity with automatic benefits, non-automatic benefits and group type (strongly cooperative $=1$, weakly cooperative $=0), R^{2}=0.45$. Parenthetical values represent the indicated variables individually regressed on group type. ${ }^{*} p<0.05,{ }^{* *} p<0.01,{ }^{* * *} p<0.001$. 
Did Non-Automatic Benefits Fail to Mediate the Effect of Group Type on Hazing Severity?

Yes; non-automatic benefits explained no unique variance in desired hazing severity (Figure 1).

Did Participants Haze More Severely as High Contributors than as Low Contributors?

Yes; participants desired more severe hazing as high contributors $(M=1.96$, $\mathrm{SD}=1.24)$ than as low contributors $(M=1.64, \mathrm{SD}=1.2)$. The effect was small: $d=0.26, F(1,128)=9.25, p<0.01$.

Did Hazing Severity Positively Correlate with Hazing Coerciveness?

Yes; the more severe the desired hazing, the greater the desired pressure, $r=0.58$, $N=132, p<0.001(M=1.61, \mathrm{SD}=1.1)$.

Did Automatic Benefits Explain Unique Variance in Hazing Severity for All Groups?

Partially; all groups evidenced a significant relationship between automatic benefits and desired hazing severity (Table 1), save the Audiophiles $(p=0.07)$.

Did Non-Automatic Benefits Fail to Explain Unique Variance in Hazing Severity in All Groups?

Yes; non-automatic benefits explained no unique variance in desired hazing severity in any of the four groups (Table 1).

\section{Table 1}

Group benefits as predictors of desired hazing severity

\begin{tabular}{lcllllr}
\hline Group name & \multicolumn{2}{l}{ Experiment 1} & \multicolumn{3}{l}{ Experiment 2} \\
\cline { 2 - 7 } & $\begin{array}{l}\text { Automatic } \\
\text { benefits }\end{array}$ & $\begin{array}{l}\text { Non-automatic } \\
\text { benefits }\end{array}$ & $N$ & $\begin{array}{l}\text { Automatic } \\
\text { benefits }\end{array}$ & $\begin{array}{l}\text { Non-automatic } \\
\text { benefits }\end{array}$ & $N$ \\
\hline Ice Walkers & $0.28^{*}$ & 0.04 & 68 & $0.32^{* *}$ & 0.08 & 89 \\
Aid Workers & $0.30^{*}$ & 0.04 & 68 & $0.32^{* *}$ & 0.12 & 89 \\
Bug Watchers & $0.46^{* *}$ & 0.00 & 64 & $0.29^{*}$ & 0.08 & 86 \\
Audiophiles & 0.24 & 0.05 & 64 & 0.11 & 0.00 & 86 \\
\hline
\end{tabular}

Within each experiment column, rows represent OLS regressions. All values are standardized beta coefficients.

${ }^{*} p<0.05,{ }^{* *} p<0.01,{ }^{* * *} p<0.001$. 


\section{Discussion}

All four basic predictions of automatic accrual theory were supported in Experiment 1. Notably, automatic (but not non-automatic) benefits were unique predictors of desired hazing severity. In addition, desired hazing severity was significantly correlated with desired hazing coerciveness. In Experiment 2, I attempted to replicate the findings of Experiment 1 while improving the stimuli and removing threats to internal validity.

\section{Experiment 2: Replication}

Only changes from Experiment 1 are noted.

\section{Participants}

175 participants (68 male) between the ages of 18 and $58(M=19.24, \mathrm{SD}=3.28)$ were recruited.

\section{Materials and Procedure}

Minor changes and clarifications were made to group descriptions, contribution primes, and benefit questions. Because group pictures may have implied sex ratios, racial makeup and other variables of unknown effect, they were removed. To capture a broader conception of obligatory group assistance, the protection benefit question was changed to ask about the extent to which new members will benefit from "mutual group aid" when in any kind of trouble. In an attempt to make the contribution primes more salient, they were modified to add information about cumulative group contribution: high contributors read that they had been with the group for three years; low contributors for four months.

For each group, one criterion for membership was modified: Instead of simply possessing group-relevant skills or attributes, participants read that prospective members were required to prove that they possessed the relevant skills necessary to be members prior to group entry. This was done to decrease the chance that differences between group types in "initiation stressfulness" represented differentially stressful tests of group-relevant skills (see the definition of hazing). Finally, in an attempt to capture greater variability in ratings, eleven-point rating scales were used (0-10). 
Results

Did Participants Haze More Severely in Strongly Cooperative Groups than in Weakly Cooperative Groups?

Yes; participants desired more severe hazing in strong groups $(M=6.12$, $\mathrm{SD}=2.5)$ than in weak groups $(M=3.9, \mathrm{SD}=2.09)$. The effect was large: $d=0.96$, $F(1,171)=49.10, p<0.001$. Sex interacted with group type: men evidenced a greater difference in desired hazing severity than women. The simple main effect was large for men $(d=1.57)$ and medium for women $(d=0.62)$, $F(1,171)=8.69, p<0.01$.

Did Automatic Benefits Appear to Mediate the Effect of Group Type on Hazing Severity?

Yes; controlling for automatic benefits reduced the amount of variance in desired hazing severity that can be uniquely explained by group type (Fig. 2).

Did Non-Automatic Benefits Fail to Mediate the Effect of Group Type on Hazing Severity?

Yes; non-automatic benefits explained no unique variance in desired hazing severity (Fig. 2).

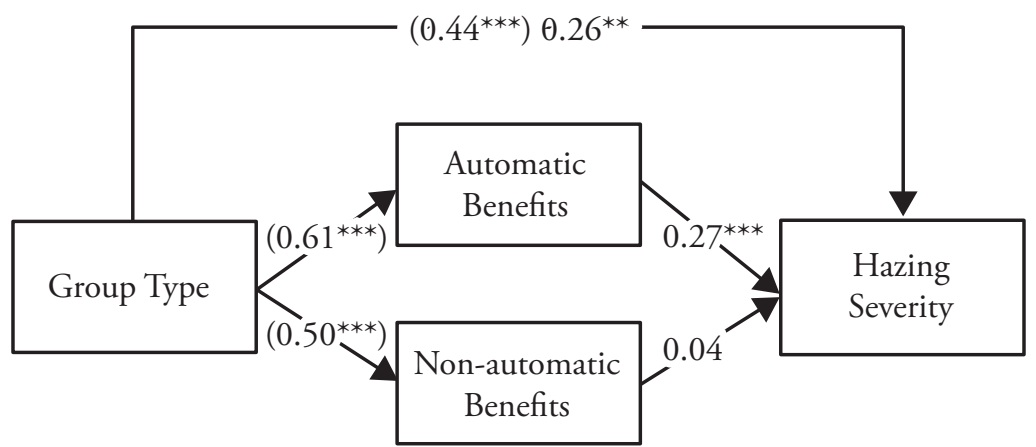

Figure 2. (From Experiment 2) All non-parenthetical values are standardized beta coefficients from an OLS regression predicting hazing severity with automatic benefits, non-automatic benefits and group type (strongly cooperative $=1$, weakly cooperative $=0), R^{2}=0.29$. Parenthetical values represent the indicated variables individually regressed on group type. ${ }^{*} p<0.05,{ }^{* *} p<0.01,{ }^{* * *} p<0.001$. 
Did Participants Haze More Severely as High Contributors than as Low Contributors?

Yes; participants desired more severe hazing as high contributors $(M=5.5$, $\mathrm{SD}=2.86)$ than as low contributors $(M=4.59, \mathrm{SD}=2.86)$. The effect was small: $d=0.32, F(1,169)=18.52, p<0.001$.

Did Hazing Severity Positively Correlate with Hazing Coerciveness?

Yes; the more severe the desired hazing, the greater the desired pressure, $r=0.39$, $p<0.001, N=175(M=4.91, \mathrm{SD}=2.61)$.

Did Automatic Benefits Explain Unique Variance in Hazing Severity for All Groups?

Partially; all groups evidenced a significant relationship between automatic benefits and desired hazing severity (Table 1$)$ save the Audiophiles $(p=0.40)$.

Did Non-Automatic Benefits Fail to Explain Unique Variance in Hazing Severity in All Groups?

Yes; non-automatic benefits explained no unique variance in desired hazing severity in any of the four groups (Table 1).

\section{General Discussion}

Although some studies have investigated the effects of hazing on hazees, these experiments are the first to explore the motivations of hazers. All four core predictions of automatic accrual theory were supported and replicated across two experiments. Automatic benefits and group contribution positively predicted desired hazing severity. Automatic benefits appeared to mediate the effect of group type on desired hazing severity, and non-automatic benefits made no independent contribution to desired hazing severity. Further, desired hazing severity positively predicted desired hazing coerciveness. Nonetheless, there are a number of substantive issues in interpreting these data as well as an interesting exception in the case of the Audiophiles.

Of the four groups used in this study, only the Audiophiles evidenced a marginal or non-significant relationship between automatic benefits and desired hazing severity. Why might this be so? The Audiophiles are the sole group with overt internal competitiveness: Participants read that the Audiophiles worked individually to compete with one another. One possibility is that constant intra-group competition creates stratification, which partitions status among group members in a publicly visible manner. If so, a status 
benefit acquired at group entry (though "automatic") might be treated as transient (i.e., likely to change due to within-group status competition).

In both experiments, group type predicted significant independent variation in desired hazing severity. Unfortunately, the manner in which group type was manipulated allowed it to represent far more than differential automatic benefits. For participants, manipulating group type likely changed expected sex ratios, age ranges, group sizes, member personality types, and so on. This makes the independent effect of "group type" ambiguous and in need of future unpacking.

Although high levels of simulated contribution increased desired hazing severity, the overall effect was small. Participants may have had difficulty simulating a long history of contribution in the context of a brief, hypothetical questionnaire. Consequently, this effect may be different in real life and deserves further exploration.

To test desired hazing severity, participants indicated how stressful they wanted an initiation to be for newcomers. While this measure may represent a decent first approximation, real-world hazing processes can be spread out over weeks, months, or years. Given this apparent variation, allowing participants to specify the stressfulness and duration of hazing may provide a more accurate indicator of desired hazing severity.

Finally, although not addressed by the experiments in this paper, automatic accrual theory may also make predictions that fall under the solidarity macro theory. For instance, given that free riding in collective actions causes cooperators to lower their own contribution levels (e.g., Fehr and Gachter, 2002), hazing may provide a cue to other veteran members that successful free riding by newcomers is effectively impossible. Providing this cue may help guarantee high levels of continuing cooperation from veterans, even during periods of changing coalition composition. As such, one possible prediction of automatic accrual theory is that if veterans are prevented from hazing, they will lower their own contribution levels.

\section{Limitations and Future Directions}

Automatic accrual theory is a logical extension of many prior theories relevant to hazing (see the discussion of the macro theories). It shares many predictions with other hazing theories, including predicting high levels of hazing in cooperative groups and hazing as a means to encourage free riders to disassociate (e.g., Young, 1967; Walker, 1968; Iannaccone, 1992; Moreland and Levine, 2002; Alcorta and Sosis, 2005). However, automatic accrual theory predicts the specific benefits that will and will not motivate hazing (i.e., automatic/ 
non-automatic benefits), directly predicts motivated coercion in hazing, and may help in explaining why hazing includes a temporary period of increased dominance over newcomers. That said, automatic accrual theory is part of a larger project to explain hazing with a high degree of generality and does not uniquely predict many particular manifestations of hazing, such as genital mutilation in adolescent initiations. The adoption of these specific practices may be due to causal processes that are separable from the ones predicted by automatic accrual theory (e.g., Sosis et al., 2007; Wilson, 2008). Further, automatic accrual theory is a preliminary theoretical effort and (if correct) will need to be complemented by other theories to generate a complete explanation of hazing. Numerous open questions remain: Is "solidarity" generation one of the functions of hazing motivation? Is hazing motivation designed to contribute to enduring dominance differences or just temporary dominance differences? To what extent is hazing motivation designed to allow for accurate inferences of intrinsic valuation in hazees?

In pursuing future studies of hazing, it is important to note that there is no large body of empirical work that directly supports any theory of hazing using operationalization and measurement. ${ }^{8}$ Thus, much of what is thought to be already known about hazing (e.g., it "increases solidarity") is derived from a wealth of descriptive and anecdotal data. While these data are interesting and important, we have very little scientific understanding of what motivates hazing and what replicable psychological effects it produces. How do we move towards creating a complete, causal theory of hazing? I have argued that a comprehensive understanding of hazing must include an investigation of hazing's motivational precursors. The experiments in this paper suggest that one such precursor may be a specific, evolved response to prevent the exploitation of automatic group benefits.

\section{Acknowledgements}

Many helpful comments were provided by Steve Gaulin, Nancy Collins, Andrew W. Delton, Richard Sosis, John Tooby and Leda Cosmides.

${ }^{8}$ This includes studies that test hazing's capacity to generate cognitive dissonance, which have produced a number of contradictory and equivocal findings. See Hautaluoma and Spungin (1974), Finer et al. (1980), Hautaluoma et al. (1991), Enge (1993) and Lodewijkx and Syriot (1997, 2001). 


\section{References}

Alcorta, C. S. and Sosis, R. (2005). Ritual, emotion, and sacred symbols: The evolution of religion as an adaptive complex. Human Nature 16, 323-359.

Allan, E. J. and DeAngelis, G. (2004). Hazing, masculinity, and collison sports: (Un)becoming heroes. In Johnson, J. and Holman, M. J. (Eds), Making the team: Inside the world of sport initiations and hazing, pp. 61-82. Canadian Scholars' Press, Toronto, ON.

Allan, E. J. and Madden, M. (2008). Hazing in view: College students at risk. Available online at http://www.hazingstudy.org/publications/hazing_in_view_web.pdf

Anderson, A. M. and Noesjirwan, J. A. (1980). Agricultural college initiations and the affirmation of rural ideology. Mankind 12, 341-347.

Aronson, E. (1988). The social animal, 5th edn. W. H. Freeman, New York, NY.

Aronson, E. and Mills, J. (1959). The effect of severity of initiation on liking for a group. The Journal of Abnormal and Social Psychology 59, 177-181.

Baier, J. L. and Williams, P. S. (1983). Fraternity hazing revisited: Current alumni and active member attitudes toward hazing. Journal of College Student Development 24, 300-305.

Barth, F. (1975). Ritual and knowledge among the Baktaman of New Guinea. Universitetsforlaget, Oslo.

Bates, A. P. and Babchuk, N. (1961). The primary group: A reappraisal. Sociological Quarterly 2, 181-191.

Bettelheim, B. (1954). Symbolic wounds: Puberty rites and the envious male (Collier Books, 1964 edn.). Free Press, Glencoe, IL.

Bey, D. R. (1972). Group dynamics and the "F.N.G." in Vietnam - a potential focus of stress. International Journal of Group Psychotherapy 22, 22-30.

Bloch, H. A. and Niederhoffer, A. (1958). The gang: A study in adolescent behavior. Philosophical Library, New York, NY.

Boyer, P. (2001). Religion explained: The evolutionary origins of religious thought. Basic Books, New York, NY.

Bryshun, J. (1997). Hazing in sport: An exploratory study of veteran/rookie relations. Masters Abstracts International, 36, 732.

Bulbulia, J. (2008). Free love: Religious solidarity on the cheap. In Bulbulia, J., Sosis, R., Harris, E., Genet, R., Genet, C. and Wyman, K. (Eds), The evolution of religion: Studies, theories, and critiques, pp. 153-160. Collins Foundation Press, Santa Margarita, CA.

Butt-Thompson, F. W. (1908). West African secret societies: Their organisation, officials and teaching (Kessinger, 2003 edn). Macmillian, New York, NY.

Carus, P. (1909). Hazing and fagging. The Open Court 23, 430-437.

Cialdini, R. B. (2001). Influence: Science and practice, 4th edn. Allyn and Bacon, Boston, MA.

Cimino, A. and Delton, A. W. (2010). On the perception of newcomers: Towards an evolved psychology of intergenerational coalitions. Human Nature 21, 186-202.

Cini, M. A., Moreland, R. L. and Levine, J. M. (1993). Group staffing levels and responses to prospective and new group members. Journal of Personality and Social Psychology 65, 723734.

Cohen, Y. A. (1964). The transition from childhood to adolescence: Cross-cultural studies of initiation ceremonies, legal systems, and incest taboos. Aldine, Chicago, IL.

Colton, L. (1993). Goat brothers, 1st edn. Doubleday, New York, NY.

Cottrell, C. A., Neuberg, S. L. and Li, N. P. (2007). What do people desire in others? A sociofunctional perspective on the importance of different valued characteristics. Journal of Personality and Social Psychology 92, 208-231.

de Albuquerque, C. L. and Eduardo, P.-M. (2004). The hazing machine: The shaping of Brazilian military police recruits. Policing and Society 14, 175-172. 
Decker, S. H. and Van Winkle, B. (1996). Life in the gang: Family, friends and violence. Cambridge University Press, Cambridge.

Delton, A. W. and Cimino, A. (2010). Exploring the evolved concept of NEWCOMER: Experimental tests of a cognitive model. Manuscript submitted for publication. Evolutionary Psychology 8, 317-335.

Delton, A. W., Robertson, T. E., Cosmides, L. and Tooby, J. (2006). Free riders and incompetents: Psychologically distinct categories. Paper presented at the 18th Annual Human Behavior and Evolution Society Conference, Philadelphia, PA.

Dornbusch, S. M. (1955). The military academy as an assimilating institution. Social Forces 33, 316-321.

Durkheim, É. (1912). Les formes élémentaires de la vie religieuse: Le système totémique en Australie (K. E. Fields, Trans. Free Press, 1995 edn). F. Alcan, Paris.

Eliade, M. (1958). Rites and symbols of initiation: The mysteries of birth and rebirth (W. R. Task, Trans. Putnam, 2005 edn). Harper Brothers, New York, NY.

Enge, R. S. (1993). Effects of severity of initiation and feedback type on potential member attraction to an organization. Dissertation Abstracts International: Section B. Sciences and Engineering 53, 4989.

Ehrhart, K. M. and Keser, C. (1999). Mobility and cooperation: On the run. Available online at http://www.cirano.qc.ca/pdf/publication/99s-24.pdf

Ermer, E. R. (2008). Coalitional support and the regulation of welfare tradeoff ratios. Dissertation Abstracts International: Section B. Sciences and Engineering 68, 361.

Fehr, E. and Gachter, S. (2002). Altruistic punishment in humans. Nature 415, 137-140.

Finer, W. D., Hautaluoma, J. E. and Bloom, L. J. (1980). The effects of severity and pleasantness of initiation on attraction to a group. Journal of Social Psychology 111, 301-302.

Gershel, J. C., Katz-Sidlow, R. J., Small, E. and Zandieh, S. (2003). Hazing of suburban middle school and high school athletes. Journal of Adolescent Health 32, 333-335.

Gordon, K., Hall, H. and Blankenship, B. (1979). Hazing revisited!? An institutional self study. Southern College Personnel Association Journal 2, 31-38.

Granzberg, G. (1972). Hopi initiation rites: A case study of the validity of the Freudian theory of culture. Journal of Social Psychology 87, 189-195.

Grimes, R. L. (2000). Deeply into the bone: Re-inventing rites of passage (2002 edn). University of California Press, Berkeley, CA.

Gurven, M. (2006). The evolution of contingent cooperation. Current Anthropology 47, 185-192.

Harmon-Jones, E. and Harmon-Jones, C. (2007). Cognitive dissonance theory after 50 years of development. Zeitschrift für Sozialpsychologie 38, 7-16.

Hautaluoma, J. E. and Spungin, H. (1974). Effects of initiation severity and interest on group attitudes. Journal of Social Psychology 93, 245-259.

Hautaluoma, J. E., Enge, R. S., Mitchell, T. M. and Rittwager, F. J. (1991). Early socialization into a work group: Severity of initiations revisited. Journal of Social Behavior and Personality 6, 725-748.

Herdt, G. H. (1998). Rituals of manhood: Male initiation in Papua New Guinea. Transaction, New Brunswick, NJ.

Honeycutt, C. (2005). Hazing as a process of boundary maintenance in an online community. Journal of Computer-Mediated Communication 10, Article 3.

Hoover, N. C. (1999). National survey: Initiation rites and athletics for NCAA sports teams. Available online at http://www.alfred.edu/sports_hazing/docs/hazing.pdf

Hoover, N. C. and Pollard, N. J. (2000). Initiation rites in American high schools: A national survey. Available online at http://www.alfred.edu/hs_hazing/docs/hazing_study.pdf

Houseman, M. (2001). Is this play? Hazing in French prepatory schools. Foocal - European Journal of Anthropology 37, 39-47. 
Hunter, T. G. (1996). The prevalence of hazing within certain Missouri interscholastic athletic programs. Masters Abstracts International 34, 2142.

Iannaccone, L. R. (1992). Sacrifice and stigma: Reducing free-riding in cults, communes, and apaother collectives. Journal of Political Economy 100, 271-291.

Jeong, E. (2003). The status of hazing in South Korean university soccer programs. Dissertation Abstracts International: Section A. Humanities and Social Sciences 64, 441.

Johnson, J. (2000). Hazed and confused: Hazing experiences versus anti-hazing policies. Case studies of two southern Ontario universities. Masters Abstracts International 38, 1604.

—. (2001). Taking it like a man: Re-examining the power structure of sport initiations. Culture and Tradition 23, 10-31.

Jones, R. L. (2004). Black haze: Violence, sacrifice, and manhood in Black Greek-letter fraternities. State University of New York Press, Albany, NY.

Keating, C. F., Pomerantz, J., Pommer, S. D., Ritt, S. J. H., Miller, L. M. and McCormick, J. (2005). Going to college and unpacking hazing: A functional approach to decrypting initiation practices among undergraduates. Group Dynamics: Theory, Research, and Practice 9, 104-126.

Lewis, D. M. H. (1992). Corporate and industrial hazing: Barbarism and the law. Labor Law Journal 43, 71-83.

Lodewijkx, H. F. M. and Syroit, J. E. M. M. (1997). Severity of initiation revisited: Does severity of initiation increase attractiveness in real groups? European Journal of Social Psychology 27, 275-300.

— . (2001). Affiliation during naturalistic severe and mild initiations: Some further evidence against the severity-attraction hypothesis. Current Research in Social Psychology 6, 90-107.

Loeb, E. M. (1929). Tribal initiations and secret societies. University of California Press, Berkeley, CA.

Malszecki, G. (2004). "No mercy shown nor asked" Toughness test or torture? Hazing in military combat units and its "collateral damage". In Johnson, J. and Holman, M. J. (Eds), Making the team: Inside the world of sport initiations and hazing, pp. 32-49. Canadian Scholars' Press, Toronto, ON.

McCarl Jr., R. S. (1976). Smokejumper initiation: Ritualized communication in a modern occupation. The Journal of American Folklore 89, 49-66.

McCauley, R. N. and Lawson, E. T. (2002). Bringing ritual to mind: Psychological foundations of cultural forms. Cambridge University Press, Cambridge.

Miller, N. (1932). Initiations. In Seligman, E. R. A. and Johnson, A. S. (Eds), Encyclopaedia of the Social Sciences, Volume 8, pp. 49-50. Macmillian, London.

Moreland, R. L. and Levine, J. M. (2002). Socialization and trust in work groups. Group Processes and Intergroup Relations 5, 185-201.

Muuss, R. E. (1970). Puberty rites in primitive and modern societies. Adolescence 5, 109-128.

Nuwer, H. (2000). High school hazing: When rites become wrongs. F. Watts, New York, NY.

Ostvik, K. and Rudmin, F. (2001). Bullying and hazing among Norwegian army soldiers: Two studies of prevalence, context, and cognition. Military Psychology 13, 17-39.

Paige, K. and Paige, J. M. (1981). The politics of reproductive ritual. University of California Press, Berkeley, CA.

Parks, G. and Brown, T. L. (2005). "In the fell clutch of circumstance": Pledging and the black Greek experience. In Brown, T. L., Parks, G. and Phillips, C. M. (Eds), African American fraternities and sororities: The legacy and the vision, pp. 437-464. University Press of Kentucky, Lexington, KY.

Pershing, J. L. (2006). Men and women's experiences with hazing in a male-dominated elite military institution. Men and Masculinities 8, 470-492.

Price, M. E., Cosmides, L. and Tooby, J. (2002). Punitive sentiment as an anti-free rider psychological device. Evolution and Human Behavior 23, 203-231. 
Robidoux, M. A. (2001). Men at play: A working understanding of professional hockey. McGillQueen's University Press, Montréal, QC.

Schlegel, A. and Barry, H. (1979). Adolescent initiation ceremonies: A cross-cultural code. Ethnology 18, 199-210.

Schopler, J. and Bateson, N. (1962). A dependence interpretation of the effects of a severe initiation. Journal of Personality 30, 633-649.

Shaw, D. L. (1992). A national study of sorority hazing incidents in selected land-grant institutions of higher learning. Dissertation Abstracts International: Section A. Humanities and Social Sciences 53, 1077.

Smith, T. S. (1964). The emergence and maintenance of fraternal solidarity. The Pacific Sociological Review 7, 29-37.

Sosis, R. (2003). Why aren't we all hutterites? Costly signaling theory and religious behavior. Human Nature 14, 91-127.

Sosis, R., Kress, H. C. and Boster, J. S. (2007). Scars for war: Evaluating alternative signaling explanations for cross-cultural variance in ritual costs. Evolution and Human Behavior 28, 234-247.

Stiff, C. and Van Vugt, M. (2008). The power of reputations: The role of third party information in the admission of new group members. Group Dynamics: Theory, Research, and Practice 12, 155-166.

Stone, R. C. (1946). A sociological study of a fraternity. Available online at http://proquest.umi. $\mathrm{com} / \mathrm{pqdweb}$ ?did=763926981 andsid $=2 \mathrm{andFmt}=1$ andclient $I d=48051$ andRQT $=309$ andVNa $\mathrm{me}=\mathrm{PQD}$

Svaan, J. (1967). The effect of fraternity hazing on college socialization. Dissertation Abstracts International: Section A. Humanities and Social Sciences 27, 3518.

Tiger, L. (1984). Men in groups, 2nd edn. Marion Boyars, New York, NY.

Tooby, J., Cosmides, L. and Price, M. E. (2006). Cognitive adaptations for n-person exchange: The evolutionary roots of organizational behavior. Managerial and Decision Economics 27, 103-129.

Tooby, J., Cosmides, L., Sell, A., Lieberman, D. and Sznycer, D. (2008). Internal regulatory variables and the design of human motivation: A computational and evolutionary approach. In Elliot, A. J. (Ed.), Handbook of approach and avoidance motivation, pp. 251-271. Psychology Press, New York, NY.

Turner, V. W. (1967). The forest of symbols: Aspects of Ndembu ritual. Cornell University Press, Ithaca, NY.

Tuzin, D. F. (1980). The voice of the Tambaran: Truth and illusion in Ilahita Arapesh religion. University of California Press, Berkeley, CA.

Van Maanen, J. and Schein, E. H. (1979). Toward a theory of organizational socialization. In Staw, B. M. (Ed.), Research in Organizational Behavior, Volume 1, pp. 209-264. JAI Press, Greenwich, CT.

van Gennep, A. (1909). Les rites de passage (M. B. Vizedom and G. L. Caffee, Trans. University of Chicago Press, 1960 edn). É. Nourry, Paris.

Van Raalte, J. L., Cornelius, A. E., Linder, D. E. and Brewer, B. W. (2007). The relationship between hazing and team cohesion. Journal of Sport Behavior 30, 491-507.

van Rooyen, L., Potgieter, F. and Mtezuka, L. (2006). Initiation school amongst the Southern Ndebele people of South Africa: Depreciating tradition or appreciating treasure? Intemational Joumal of Adolescence and Youth 13, 13-41.

Vigil, J. D. (1996). Street baptism: Chicano gang initiation. Human Organization 55, 149-153.

Waldron, J. J. and Kowalski, C. L. (2009). Crossing the line: Rites of passage, team aspects, and the ambiguity of hazing. Research Quarterly for Exercise and Sport 80, 291-302. 
Walker, M. G. (1968). Organizational type, rites of incorporation, and group solidarity: A study of fraternity hell week. Dissertation Abstracts International: Section A. Humanities and Social Sciences 29, 689.

Webster, H. (1908). Primitive secret societies: A study in early politics and religion (Kessinger, 2006 edn). Macmillian, New York, NY.

Weisfeld, G. (1997). Puberty rites as clues to the nature of human adolescence. Cross-Cultural Research: The Journal of Comparative Social Science 31, 27-54.

Whitehouse, H. (1996). Rites of terror: Emotion, metaphor and memory in Melanesian initiation cults. Journal of the Royal Anthropological Institute 2, 703-715.

- (2004). Modes of religiosity: A cognitive theory of religious transmission. AltaMira Press, Walnut Creek, CA.

Whiting, J. W. M., Kluckhohn, R. and Anthony, A. (1958). The function of male initiation ceremonies at puberty. In Maccoby, E., Newcomb, T. M. and Hartley, E. L. (Eds), Readings in Social Psychology, pp. 359-370. Henry Holt, New York, NY.

Wiessner, P. W., Tumu, A. and Pupu, N. (1998). Historical vines: Enga networks of exchange, ritual, and warfare in Papua New Guinea. Smithsonian Institution Press, Washington, DC.

Wilson, C. G. (2008). Male genital mutilation: An adaptation to sexual conflict. Evolution and Human Behavior 29, 149-164.

Winslow, D. (1999). Rites of passage and group bonding in the Canadian airborne. Armed Forces and Society 25, 429-457.

Wintrup, G. (2004). Sportization and hazing: Global sport culture and the differentiation of initiation from harassment in Canada's sport policy. Masters Abstracts International 42, 1559.

Young, F. W. (1965). Initiation ceremonies: A cross-cultural study of status dramatization. BobbsMerrill, Indianapolis, IN.

$\theta$ 
